\title{
International Yearbook for Hermeneutics / Internationales Jahrbuch für Hermeneutik
}

\author{
Focus: Reading / Schwerpunkt: Lesen \\ Ed. by Günter Figal
}

[Internationales Jahrbuch für Hermeneutik. Band 12. Schwerpunkt: Lesen.]

Veröffentlicht auf Englisch.

Das Internationale Jahrbuch für Hermeneutik repräsentiert eine der Hauptströmungen in der Philosophie der Gegenwart und der angrenzenden Disziplinen. Es versammelt Studien zu Fragen des Verstehens und Interpretierens auf allen Gebieten, einschließlich der Philosophie, Theologie, Rechtswissenschaften und Wissenschaftstheorie wie der Sprach- und

International Yearbook for Hermeneutics

Internationales Jahrbuch für Hermeneutik

$$
\text { Focus: Reading }
$$

Schwerpunkt: Lesen

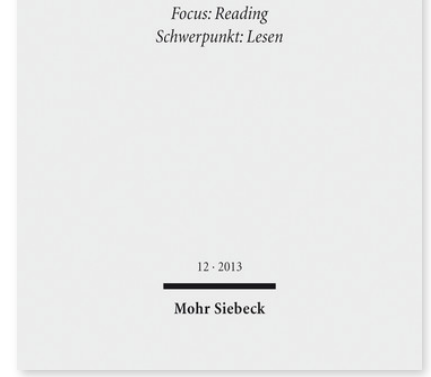

2013. VI, 264 Seiten. IYH 12

ISBN 978-3-16-152806-4

DOI 10.1628/978-3-16-152806-4

eBook PDF $114,00 €$

ISBN 978-3-16-152711-1

fadengeheftete Broschur $114,00 €$
Kulturwissenschaften. Das Jahrbuch nimmt Beiträge zu aktuellen Debatten ebenso auf wie solche zur Ideengeschichte von der Antike bis zur Gegenwart. Der diesjährige Band widmet sich dem Thema »Lesen".

Inhaltsübersicht

Schwerpunkt: Lesen

Heike Gfrereis: Nicht-Lesen. Die Entzauberung einer alten Vorstellung - Bernhard Zimmermann: Ovid liest Klassiker - John Sallis: Doubly Slow Reading - Luca Crescenzi: Sich wandelnde Wahrheit und selbstkritisches Lesen. Nietzsche-Variationen Ben Vedder: The Historicity of Reading - Dennis J. Schmidt: The Garden of Letters. Reading Plato's Phaedrus on Reading Daniela Vallega-Neu: At the Limit of Word and Thought. Reading Heidegger's Das Ereignis - Gert-Jan van der Heiden: Reading Bartleby, Reading Ion. On a Difference between Agamben and Nancy - Nicholas Davey: Critical Excess and the Reasonableness of Interpretation - David Espinet: Read thyself! Hobbes, Kant und Husserl über die Grenzen der Selbsterfahrung

Beiträge

Andrea Kern: Das Kunstwerk zwischen Autonomieanspruch und Wahrheit - Alexander Schnell: Kontingenz und Entzug. Zum Transzendentalismus Heideggers - Enrique V. Muñoz Pérez: Heidegger und Scheler. Ein vergessener Bezug - Csaba Olay: Die Überlieferung der Gegenwart und die Gegenwart der Überlieferung. Heidegger und Gadamer über Tradition - Eberhard Geisler: Hölderlin und die Gabe

Günter Figal Geboren 1949; 1989-2002 Professor für Philosophie an der Universität Tübingen; 2002-17 Professor für Philosophie an der Universität Freiburg i.Br.; seit 2017 emeritiert.

Jetzt bestellen:

https://mohrsiebeck.com/buch/international-yearbook-for-hermeneutics-internationales-jahrbuch-fuer-hermeneutik9783161528064?no_cache=1

order@mohrsiebeck.com

Telefon: $+49(0) 7071-923-17$

Telefax: $+49(0) 7071-51104$ 